\title{
Development and Characterization of an Environmentally Friendly Process Sequence (Autohydrolysis and Organosolv) for Wheat Straw Delignification
}

\author{
Héctor A. Ruiz • Denise S. Ruzene • Daniel P. Silva • \\ Fernando F. Macieira da Silva • António A. Vicente • \\ José A. Teixeira
}

Received: 1 May 2010 / Accepted: 10 January 2011/

Published online: 28 January 2011

(C) Springer Science+Business Media, LLC 2011

\begin{abstract}
The present work describes the delignification of wheat straw through an environmentally friendly process resulting from sequential application of autohydrolysis and organosolv processes. Wheat straw autohydrolysis was performed at $180^{\circ} \mathrm{C}$ during $30 \mathrm{~min}$ with a liquid-solid ratio of $10(\mathrm{v} / \mathrm{w})$; under these conditions, a solubilization of $44 \%$ of the original xylan, with $78 \%$ of sugars as xylooligosaccharides of the sum of sugars solubilized in the autohydrolysis liquors generated by the hemicellulose fraction hydrolysis. The corresponding solid fraction enrichment with $63.7 \%$ of glucan and $7.55 \%$ of residual xylan was treated with a $40 \%$ ethanol and $0.1 \% \mathrm{NaOH}$ aqueous solution at a liquid-solid ratio of $10(\mathrm{v} / \mathrm{w})$, with the best results obtained at $180^{\circ} \mathrm{C}$ during $20 \mathrm{~min}$. The highest lignin recovery, measured by acid precipitation of the extracted lignin, was $3.25 \mathrm{~g} / 100 \mathrm{ml}$. The lignin obtained by precipitation was characterized by FTIR, and the crystallinity indexes from the native cellulose, the cellulose recovered after autohydrolysis, and the cellulose obtained after applying the organosolv process were obtained by X-ray diffraction, returning values of $21.32 \%, 55.17 \%$, and $53.59 \%$, respectively. Visualization of the fibers was done for all the processing steps using scanning electron microscopy.
\end{abstract}

Keywords Organosolv process $\cdot$ Delignification $\cdot$ Wheat straw $\cdot$ Autohydrolysis $\cdot$ Extraction

\section{Introduction}

In recent years, lignocellulosic materials (LCM) have become an interesting raw material for ethanol production, and for chemical, paper, pharmaceutical, and biomaterials

$\overline{\text { H. A. Ruiz } \cdot \text { F. F. M. da Silva } \cdot \text { A. A. Vicente } \cdot \text { J. A. Teixeira }(\triangle)}$

IBB-Institute for Biotechnology and Bioengineering, Centre of Biological Engineering,

University of Minho, Campus de Gualtar, 4710-057 Braga, Portugal

e-mail: jateixeira@deb.uminho.pt

D. S. Ruzene • D. P. Silva

ITP-Instituto de Tecnologia e Pesquisa, Tiradentes University, Campus Farolândia, 49032-490 Aracaju, SE, Brazil 
industries. The efficient separation of LCM mains components is one of the major obstacles for its utilization as renewable resource. Conversion of LCM into chemicals requires the development of commercially viable technologies that allow efficient and clean fractionation into its components $[1,2]$ that will be further transformed into high value-added products according to the so-called biorefinery concept. In order to become a viable alternative to, e.g., a petrochemical refinery, a biorefinery must be competitive and cost-effective [3].

Wheat straw is one of the most abundant agricultural residues which is generated in huge quantities around the world every year. Although straw yield depends on the specific varieties harvested and is widely affected by agronomic and climatic factors, an average ratio of $1.3 \mathrm{~kg}$ of straw per $\mathrm{kg}$ of grain is found for the most common varieties, representing around 611 million tons of wheat worldwide in 2007 [4-6]; these amounts are significant enough to consider wheat straw as a complementary source of raw material.

Lignin is the most abundant aromatic heterogeneous polymer formed by phenolic compounds and its characteristic structure depends to the extractive method and the plant source. Lignin is made up of three precursors: trans-coniferyl, trans-sinapyl, and transp-coumaryl alcohols. Gymnosperm lignins show predominance of guaiacyl groups, angiosperms lignins contain guaiacyl-syringyl groups and lignins from grasses contain guaiacyl-syringyl-p-hydroxyphenyl groups [7]. Lignin is an essential component of higher plants and has a very complex structure whose function is to provide rigidity and cohesion to the material cell wall, to confer water-impermeability to xylem vessels, and to offer physico-chemical resistance against microbial attack $[8,9]$.

The chemical separation of lignin from cellulose has been termed "delignification" and is a complex processes. Industrially, lignin is found during the process of papermaking from wood and commercial lignin is divided into two categories. The first category comprises conventional or sulfur-containing lignins, which include kraft lignin and lignosulfonates; these products have been available for many years. Nowadays, lignin in amounts larger than 70 million tonnes per year is produced by kraft process worldwide. However, the major disadvantages of the kraft process include the low pulp yield, the high consumption of bleaching chemicals to obtain bright pulp, and formation of odorous gases [10]. From that amount, $99 \%$ are burnt in chemical recovery furnaces and, consequently, not recovered for industrial applications [8, 11]. The second category comprises non-sulfur lignins obtained from many different processes, most of which are not yet commercially implemented: organosolv lignins, soda lignins, steam explosion lignins, hydrolysis lignins (mainly from biofuel production), and oxygen delignification lignins. Almost all lignins extracted from lignocellulosic materials from the pulp and paper industry are burned to generate energy, only a small amount $(1-2 \%)$ is commercially used in a wide range of products. On the other hand, an alternative for the pulping processes utilizing aqueous organic solvents, known as organosolv, have been studied in the last 30 years as an alternative to conventional chemical processes of pulping [11-16]. The organosolv process was developed by General Electric Company in the 1970s to make a clean biofuel for turbine generators. Consequently, the Canadian pulp and paper industry performed modifications to the process resulting in the Alcell pulping process, and different demonstration plants have been developed. Actually, the organosolv process has been developed as part of a commercial lignocelluloses biorefinery technology known as the Lignol process. Lignol is a pilot plant that obtained several high value products a cost-effective process in which solvents were recovered and recycled at the end of the process [17-19].

Organosolv (organic solvent-based) pulping is an environmentally friendly chemical pulping method compared with the kraft and sulfite processes; in which delignification of biomass (usually wood) is performed by an organic solvent (frequently ethanol) or solvent 
plus water system $[14,20,21]$ which involves treating the raw LCM at temperatures in the range of $180-200^{\circ} \mathrm{C}$. During the organosolv process, the lignin structure is broken into smaller parts and dissolved from the raw material and separated in the form of liquor rich in phenolic compounds that represents the process effluent [20,21]. This lignin can be isolated and has the advantage of being a relatively pure product with excellent properties which may be used as precursor in the production of various commercial products such as: vanillin, syringaldehyde, phenol, benzene and substituted phenols, dispersants, emulsifiers and chelanting agents, antioxidants, pesticides, fertilizers, vegetal charcoal, polymers, adhesives, concrete additives, components for resins, animal vitamin supplements, among others $[9,17,19-21]$. The main advantages reported for organosolv process are: (a) It can economically operate at a smaller scale than the kraft process, (b) significantly lower environmental impact (no sulfur-containing substances), (c) can be used with any type of woody and nonwoody raw material, (d) the properties of the resulting pulp are similar to those of kraft pulp, with a higher extraction yield although with a lower lignin content, (e) the production of by-products of potentially significant commercial interest, (f) the pulp is whiter and more readily bleached than kraft pulp, which saves bleaching reagents, $(\mathrm{g})$ the pulp is easier to beat, (h) the presence of organic compounds in the liquors reduces their viscosity, thus, improving both their handling and the penetration of the impregnation chemicals into the chips, (i) the solvents can be efficiently recovered, (j) the process uses less water, energy and reagents than traditional alternatives, (k) raw materials are more efficiently used (virtually the whole mass can be used for some purpose) [12, 20, 22-24].

Additionally, the presence of lignin is known to reduce the efficiency and is one of the major barriers in enzymatic hydrolysis moreover, the other phenomena is the adsorption of cellulases onto lignin is believed to be due to hydrophobic and different interaction lignin-enzyme. Thus, the increased removal of lignin could be advantageous compared with other pretreatments and it has been shown that the solid fiber remaining with residual lignin is highly susceptible to cellulose hydrolysis extent of cellulose saccharification being greater than $90 \%$ of theoretical maximum and decreasing enzyme losses, when the organosolv process is used [25-28].

The aim of this work was to develop and characterized environmentally friendly process sequence, involving autohydrolysis and organosolv process for delignification of wheat straw. Extracted lignin was further characterized following acid precipitation.

\section{Materials and Methods}

\section{Raw Material}

Wheat straw was kindly provided by a local farmer (Elvas, Portugal). The wheat straw was cut into small pieces $(1-3 \mathrm{~cm})$. Samples were milled to pass a $0.5-\mathrm{mm}$ screen. Aliquots from the homogenized wheat straw lot were subjected to moisture determination (drying at $105^{\circ} \mathrm{C}$ to constant weight), quantitative acid hydrolysis with $5 \mathrm{ml}$ of $72 \%(w / w)$ sulfuric acid for $1 \mathrm{~h}$, and quantitative posthydrolysis with $4 \%$ sulfuric acid (adding water until $148.67 \mathrm{~g}$ ) at $121^{\circ} \mathrm{C}$ during $60 \mathrm{~min}$. Before HPLC analysis, the solid residue from posthydrolysis process was recovered by filtration and considered as Klason lignin [29]. The monosaccharides sugars and acetic acid contained in hydrolysates were determined by HPLC in order to estimate the contents of samples in cellulose (as glucan), xylan, arabinan, and acetyl groups. The moisture of wheat straw was considered as water in the material balances. Chromatographic separation was performed using a Metacarb $87 \mathrm{H}$ column $(300 \times$ $7.8 \mathrm{~mm}$, Varian, USA) under the following conditions: mobile phase $0.005 \mathrm{~mol} / 1$ sulfuric 
acid, flow rate $0.7 \mathrm{ml} / \mathrm{min}$, and column temperature $60^{\circ} \mathrm{C}$ using a Jasco chromatograph 880-PU intelligent pump (Jasco, Tokyo, Japan) equipped with a Jasco 830-IR intelligent refraction-index detector (Jasco, Tokyo, Japan) and a Jasco AS-2057 Plus intelligent auto sampler (Jasco, Tokyo, Japan). The volume injected was $20 \mu \mathrm{l}$.

\section{Autohydrolysis Process}

Milled wheat straw samples with a particle size distribution of ( $>1 \mathrm{~mm}, 10 \%$; between 1 and $0.5 \mathrm{~mm}, 40 \%$, between 0.5 and $0.3 \mathrm{~mm}, 40 \%$; $<0.3 \mathrm{~mm}, 10 \%$ ) and water were mixed in order to obtain a ratio 10:1 liquid/solid and treated in a 3.751 total volume stainless steel reactors (Parr Instruments Company, Moline, Illinois, USA) with PID temperature control and a double sixblade turbine impeller. The moisture content of wheat straw was considered as water in the material balances. The reactor was filled and heated to $180^{\circ} \mathrm{C}$ at a heating rate of $3^{\circ} \mathrm{C} / \mathrm{min}$ until the desired temperature was reached, the reaction time was $30 \mathrm{~min}$; these conditions were previously evaluated by Ruiz et al. [30]. After completing the reaction time, the reactor was cooled down at a rate of about $3.2^{\circ} \mathrm{C} / \mathrm{min}$. The agitation speed was set at $135 \mathrm{rpm}$. At the end of treatment, the liquid and solid phases were separated by centrifugation and the solid residues were washed with distilled water. The liquid was analyzed by HPLC with a MetaCarb $87 \mathrm{H}(300 \times 7.8 \mathrm{~mm}$, Varian, USA $)$ column at $45^{\circ} \mathrm{C}$ using a Jasco chromatograph equipped with refraction-index detector (Jasco, Tokyo, Japan); the mobile phase was $0.005 \mathrm{~mol} / 1$ sulfuric acid at a flow rate of $0.6 \mathrm{ml} / \mathrm{min}$. The samples were analyzed for glucose, xylose, arabinose, 5-hydroxymethylfurfural (HMF), furfural and acetic acid. Sugars and compounds concentration were determined using calibration curves of these pure compounds. A second aliquot of liquors $(20 \mathrm{ml}$ ) was subjected to quantitative posthydrolysis (with $4 \%$ $\mathrm{H}_{2} \mathrm{SO}_{4}$ at $121^{\circ} \mathrm{C}$ during $60 \mathrm{~min}$ ) before HPLC analysis. The increase in the concentrations of monosaccharides and acetic acid caused by posthydrolysis measured the concentrations of oligomers and acetyl groups bound to oligosaccharides [31]. Equations 1 to 10 were used to calculate: (a) the percentage of feedstock xylan converted into concentrations of xylooligosaccharides $\left(\mathrm{XOS}_{\mathrm{C}}\right)$, xylose $\left(\mathrm{Xyl}_{\mathrm{C}}\right)$ and furfural $\left(\mathrm{F}_{\mathrm{C}}\right)$; (b) the percentage of feedstock arabinan converted into arabinooligosaccharides $\left(\mathrm{AOS}_{\mathrm{C}}\right)$ and arabinose $\left(\mathrm{Ara}_{\mathrm{C}}\right)$; (c) the percentage of feedstock acetyl groups converted into acetyl groups linked to oligosaccharides $\left(\mathrm{AcO}_{\mathrm{C}}\right)$ and acetic acid $\left(\mathrm{Acl}_{\mathrm{C}}\right)$; and $(\mathrm{d})$ the percentage of feedstock glucan converted into glucooligosaccharides $\left(\mathrm{GO}_{\mathrm{C}}\right)$, glucose $\left(\mathrm{Glu}_{\mathrm{C}}\right)$, and $\mathrm{HMF}\left(\mathrm{HMF}_{\mathrm{C}}\right)$.

$$
\begin{aligned}
& \mathrm{XOS}_{\mathrm{C}}=\frac{132}{150} \cdot \frac{\mathrm{XOS}}{\mathrm{Xn}_{\mathrm{FS}}} \cdot \frac{\mathrm{W}_{\mathrm{L}}}{\mathrm{W}_{\mathrm{FS}}} \cdot 10 \\
& \mathrm{Xyl}_{\mathrm{C}}=\frac{132}{150} \cdot \frac{\mathrm{Xyl}}{\mathrm{Xn}_{\mathrm{FS}}} \cdot \frac{\mathrm{W}_{\mathrm{L}}}{\mathrm{W}_{\mathrm{FS}}} \cdot 10 \\
& \operatorname{AOS}_{C}=\frac{132}{150} \cdot \frac{\operatorname{AOS}}{\operatorname{Arn}_{\mathrm{FS}}} \cdot \frac{\mathrm{W}_{\mathrm{L}}}{\mathrm{W}_{\mathrm{FS}}} \cdot 10 \\
& \operatorname{Ara}_{\mathrm{C}}=\frac{132}{150} \cdot \frac{\operatorname{Ara}}{\operatorname{Arn}_{\mathrm{FS}}} \cdot \frac{\mathrm{W}_{\mathrm{L}}}{\mathrm{W}_{\mathrm{FS}}} \cdot 10 \\
& \mathrm{~F}_{\mathrm{C}}=\frac{132}{96} \cdot \frac{\mathrm{F}}{\mathrm{Xn}_{\mathrm{FS}}} \cdot \frac{\mathrm{W}_{\mathrm{L}}}{\mathrm{W}_{\mathrm{FS}}} \cdot 10
\end{aligned}
$$




$$
\begin{aligned}
\mathrm{AcO}_{\mathrm{C}} & =\frac{43}{60} \cdot \frac{\mathrm{AcOS}}{\mathrm{Acl}_{\mathrm{FS}}} \cdot \frac{\mathrm{W}_{\mathrm{L}}}{\mathrm{W}_{\mathrm{FS}}} \cdot 10 \\
\mathrm{Acl}_{\mathrm{C}} & =\frac{43}{60} \cdot \frac{\mathrm{Ace}}{\mathrm{Acl}_{\mathrm{FS}}} \cdot \frac{\mathrm{W}_{\mathrm{L}}}{\mathrm{W}_{\mathrm{FS}}} \cdot 10 \\
\mathrm{GO}_{\mathrm{C}} & =\frac{162}{180} \cdot \frac{\mathrm{GOS}}{\mathrm{Gln}} \cdot \frac{\mathrm{W}_{\mathrm{LS}}}{\mathrm{W}_{\mathrm{FS}}} \cdot 10 \\
\mathrm{Glu}_{\mathrm{C}} & =\frac{162}{180} \cdot \frac{\mathrm{Glu}}{\mathrm{Gln}} \cdot \frac{\mathrm{W}_{\mathrm{LS}}}{\mathrm{W}_{\mathrm{FS}}} \cdot 10 \\
\mathrm{HMF}_{\mathrm{C}} & =\frac{162}{126} \cdot \frac{\mathrm{HMF}}{\mathrm{Gln}} \cdot \frac{\mathrm{W}_{\mathrm{LS}}}{\mathrm{W}_{\mathrm{FS}}} \cdot 10
\end{aligned}
$$

The following terms correspond to the stoichiometric factor for the conversion of xylose into xylan or arabinose into arabinan (132/150), furfural into xylan (132/96), acetyl groups into acid acetic (43/60), glucose into glucan (162/180), and HMF into glucan $(162 / 126)$ [32-34]. The solid residues were washed, air-dried, and milled to a particle size $<0.5 \mathrm{~mm}$ in order to make certain quantitative polysaccharide hydrolysis. Milled samples were assayed for glucan, xylan, arabinan, and acetyl groups; the acid-insoluble residue was considered as klason lignin using the same methods as for raw material analysis.

\section{Delignification and Lignin Recovery}

The solid residue obtained from autohydrolysis was delignified with an organosolv process by a solvent consisting of an aqueous solution of $40 \%(v / v)$ ethanol and $0.1 \%(w / v) \mathrm{NaOH}$ conditions (Table 1). The solid/liquid ratio was fixed at 1:10 w/v. These experiments were carried out in $160 \mathrm{ml}$ total volume stainless steel cylinders reactors. The reactor was closed and mounted vertically and then submerged in a Julabo oil bath open heating circulator (JULABO Labortechnik GmbH, Seelbach, Germany) with PID temperature control, previously heated to the desired reaction temperature (see Table 1). At the end of the desired reaction time (see Table 1), the reactor was removed from oil bath and cool down by soaking in an ice-water bath for $5 \mathrm{~min}$. The solid and liquid were separated via vacuum filtration. The filtrate was distilled to recover the ethanol at low temperature. Recovered ethanol could be reused. In order to recover lignin, the $\mathrm{pH}$ of concentrated liquor was

Table 1 Set conditions for delignification and quantification of the precipitated lignin mass (liquid/solid ratio $1: 10$, aqueous solution of $40 \%$ ethanol and $0.1 \% \mathrm{NaOH}$ )

\begin{tabular}{lcccc}
\hline Sample & ${\text { Temperature }\left({ }^{\circ}\right)}^{*}$ & Time $(\mathrm{min})$ & Precipitated lignin mass $(\mathrm{g})$ & Yield $^{\mathrm{a}}(\mathrm{g} / 100 \mathrm{ml})$ \\
\hline 1 & 180 & 20 & 0.65 & 3.25 \\
2 & 180 & 40 & 0.51 & 2.55 \\
3 & 190 & 30 & 0.44 & 2.2 \\
4 & 200 & 20 & 0.42 & 2.1 \\
5 & 200 & 40 & 0.38 & 1.9 \\
\hline
\end{tabular}

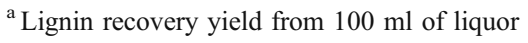


lowered with $0.3 \mathrm{~mol} / 1$ hydrochloric acid to a point where the lignin was no longer soluble and precipitation took place $(\mathrm{pH}=1.6)$. The precipitated lignin was recovered by centrifugation at $3500 \mathrm{rpm}$ for $15 \mathrm{~min}$, water washed, air-dried at $60^{\circ} \mathrm{C}[1,35]$.

Characterization of Liquors and Lignin Recovery from Organsolov Process

The concentration of the phenolic acids-vanillic, ferulic, syringic, gallic and $p$ hydroxybenzoic - in the liquors was determined by HPLC using a Jasco chromatograph 2080-PU intelligent pump (Jasco, Tokyo, Japan) equipped with a Jasco 2070-UV intelligent UV-VIS detector (Jasco, Tokyo, Japan) at $276 \mathrm{~nm}$ and a Jasco AS-2057 Plus intelligent auto sampler (Jasco, Tokyo, Japan) with a Nucleosil 120-5 $\mathrm{C}_{18}(5 \mu \mathrm{m}$ particle size, Macherey-Nagel, Düren, Germany) column. The samples were filtered in $0.45 \mu \mathrm{m}$ Millipore membrane and injected in the chromatograph under the following conditions: column at room temperature; acetonitrile/water 1:8 containing $10 \mathrm{~g} / 1$ acetic acid and $\mathrm{pH}$ adjusted to 2.5 by $\mathrm{H}_{3} \mathrm{PO}_{4}$ addition) as mobile phase; a flow rate of $0.9 \mathrm{ml} / \mathrm{min}$ and injection volume of $20 \mu \mathrm{l}$ [30].

\section{Fourier-Transform Infrared}

Fourier-transform Infrared (FTIR) spectra were obtained on an FTIR spectrophotometer (FTLA 2000 series, ABB Bomem Inc., Quebec, Canada). The conditions of analysis were as follows: resolution $4 \mathrm{~cm}^{-1}$, co-adding 20 scans and frequency range of $400-4000 \mathrm{~cm}^{-1}$ using a $\mathrm{KBr}$ disk containing $1 \%$ finely ground samples.

\section{X-ray Diffraction Analysis and Crystallinity}

Cellulose crystallinity of wheat straw treated with autohydrolysis and organosolv process were analyzed an X-ray diffractometry (Bruker D8 Discover, USA). The operating voltage and current were $40 \mathrm{kV}$ and $60 \mathrm{~mA}$, respectively. The crystallinity index (CI) was defined using the equation $\mathrm{CI}=\left(I_{002}-I_{\mathrm{am}}\right) / I_{002} \times 100$, where $I_{002}$ is the maximum intensity $(2 \theta$, $\left.22.6^{\circ}\right)$ of the (002) lattice diffraction and $I_{\mathrm{am}}$ is the intensity of the amorphous diffraction $\left(2 \theta, 18.7^{\circ}\right)$, respectively $[36,37]$.

\section{Scanning Electron Microscopy}

The scanning electron microscopy (SEM) surface of wheat straw treated with autohydrolysis and organosolv processes were visualized by a scanning electron microscope (Nova NanoSEM 200, Netherlands) and photographed. Samples were coated with layer of gold by sputtering with an accelerating voltage varying to $15 \mathrm{kV}$.

\section{Results and Discussion}

\section{Composition of Raw Material}

The wheat straw used had the following composition ( $\%$ dry weight, $w / w): 37.4 \%$ cellulose (glucan), 29.4\% xylan, 1.9\% arabinan, 2.5 acetyl group, $23.6 \%$ lignin, and $2.1 \%$ ashes. The amounts of xylan, arabinan, and acetyl groups correspond to the content of hemicellulose. 
This chemical composition is in good agreement with other values found in the literature for this material $[1,38,39]$.

\section{Effect of Autohydrolysis on the Composition on the Liquid Phase}

The conditions of time, temperature and particle size distribution used during the process of autohydrolysis for wheat straw sugars solubilization were established in a previous work Ruiz et al. [30]. Autohydrolysis can be conceived as an environmentally friendly process that caused a substantial fractionation into non-volatile components including monosaccharides (xylose, arabinose, and glucose), oligosaccharides (xylooligosaccharidesXOS, arabinooligosaccharides-ArOS, glucooligosaccharides-GOS, and acetyl groups linked to oligosaccharides-AcOS); and volatile components mainly acetic acid, furfural and HMF [40]. The concentrations ( $\mathrm{g} / \mathrm{l})$ of the liquid phase components derived principally from wheat straw hemicellulose fractions by autohydrolysis at $180^{\circ} \mathrm{C}$ and $30 \mathrm{~min}$ were $14.72 \pm 0.095,0.86 \pm 0.059,1.25 \pm 0.074,1.94 \pm 0.003,1.25 \pm 0.006,2.04 \pm 0.030$ and $0.636 \pm$ 0.066 for XOS, ArOS, AcOS, xylose, arabinose, acetic acid, and furfural, respectively. The yields of soluble sugars (XOS and xylose) of the original xylan were $44 \%$ and $5.8 \%$, respectively. The XOS yield is in agreement with previous studies reported by Nabarlatz et al. [41] and Carvalheiro et al. [32] with feedstock yields of $45 \%$ and $58 \%$, respectively. The recovery oligomers, mainly XOS, represented the $78 \%$ of the sum of sugars solubilized in the autohydrolysis liquors generated by the hemicellulose fraction hydrolysis. As can be observed, the hemicellulose can be selectively removed from wheat straw by the autohydrolysis. Arabinose rapidly released from hemicelluloses demonstrating that this fraction showed high susceptibility to hydrolysis reactions, the yields of soluble sugars (ArOS and arabinose) were $39.83 \%$ and $57.89 \%$ respectively, Gullón et al. [42] reported a value of $28.2 \%$ for rye straw. Xylose and arabinose yields obtained in the liquid product were not high because they readily decomposed into furfural at the reaction conditions. Yields for AcOS and acetic acid were 35.83\% and 58.58\%, respectively, these results are in agreement with other reported data [42, 43]; the low content of acetyl groups can be partially explained by the wheat straw composition, related with the low recovery production of degradation products as furfural yield (2.94\%).

In contrast to hemicellulose components, the effect of the autohydrolysis reaction on the cellulose (glucan) basically remained in the solid phase and only a small part was depolymerized to oligomers and glucose. The sugars concentration $(\mathrm{g} / \mathrm{l})$ were $1.76 \pm 0.085$, $0.51 \pm 0.009$, and $0.122 \pm 0.002$ for GOS, glucose and HMF, respectively. The glucooligosaccharides and glucose yields were $4.23 \%$ and $1.22 \%$, respectively and the HMF as degradation product was $0.41 \%$, demonstrating that only a minor part of the glucose present in the liquor was degraded by the autohydrolysis process.

\section{Effect of Autohydrolysis on the Composition of the Solid Phase}

The cellulose (glucan) content in the solid residue was of $63.7 \%$, xylan $7.55 \%$, arabinan $0.29 \%$, acetyl groups $1.51 \%$ and klason lignin $26.91 \%$, revealing that the glucan was almost not affect by the autohydrolysis process and a solid residue with increased glucan was obtained. This decrease could be correlated to the solubilization of hemicellulose components and these results are in agreement with the data reported for the similar feedstock; Gullón et al. [42] observed a similar behavior for rye straw. The klason lignin content follows a similar pattern to glucan and the majority of the lignin content remains in the solid phase. 
Characterization of Liquor and Lignin Recovery

The obtained solid phase after autohydrolysis process is treated using the organosolv process and extracted/solubilized lignin is recovered by precipitation with hydrochloric acid. In the organosolv process using ethanol pulping, removal of lignin depends not only on cleavage of ether bonds in lignin macromolecules, but also on the ability of aqueous ethanol solution to dissolve lignin fragments. The results of lignin describing the effect of operation variables (time and temperature) on the amount of extracted lignin (quantified by acid precipitation) by ethanol pulping are shown in Table 1. Although it has been previously shown that temperature, time, and $\mathrm{pH}$ were the dominant factors in lignin extraction [1,44], our results indicate that a temperature increase up to $190^{\circ} \mathrm{C}$ did not influence lignin precipitation and that the highest yield of precipitated mass occurred at $180^{\circ} \mathrm{C}$ for processing times between 20 and $40 \mathrm{~min}$. This can be explained by the variation of the phenolic acids in the liquors. Five phenolic acids were quantified in the liquors obtained after of organosolv process. The choice for these compounds was based on the fact that there are main acids present in the wheat straw [45]. The removal profiles obtained (Fig. 1) allow evaluating the effect of increasing time and temperature on the concentration of lignin-derived compounds in the liquor. Figure 1 shows that temperature is not the only factor influencing lignin extraction [46] as the chemical structure of the compounds being extracted is also relevant. The highest removal was observed for vanillic acid $(0.19 \mathrm{~g} / \mathrm{l})$ and the lowest for syringic acid $(0.004 \mathrm{~g} / \mathrm{l})$. In the case of ferulic acid, the removal profile was different from those observed for the other acids, as a significant increase in its extraction was observed when time was increased from 20 to $40 \mathrm{~min}$, at $200^{\circ} \mathrm{C}$. The extracted amounts of $p$-hydroxybenzoic and gallic acids showed an increment of 0.003 to $0.039 \mathrm{~g} / 1$ and 0.065 to $0.087 \mathrm{~g} / \mathrm{l}$, respectively. The values obtained for the extraction of phenolic acids as a function of

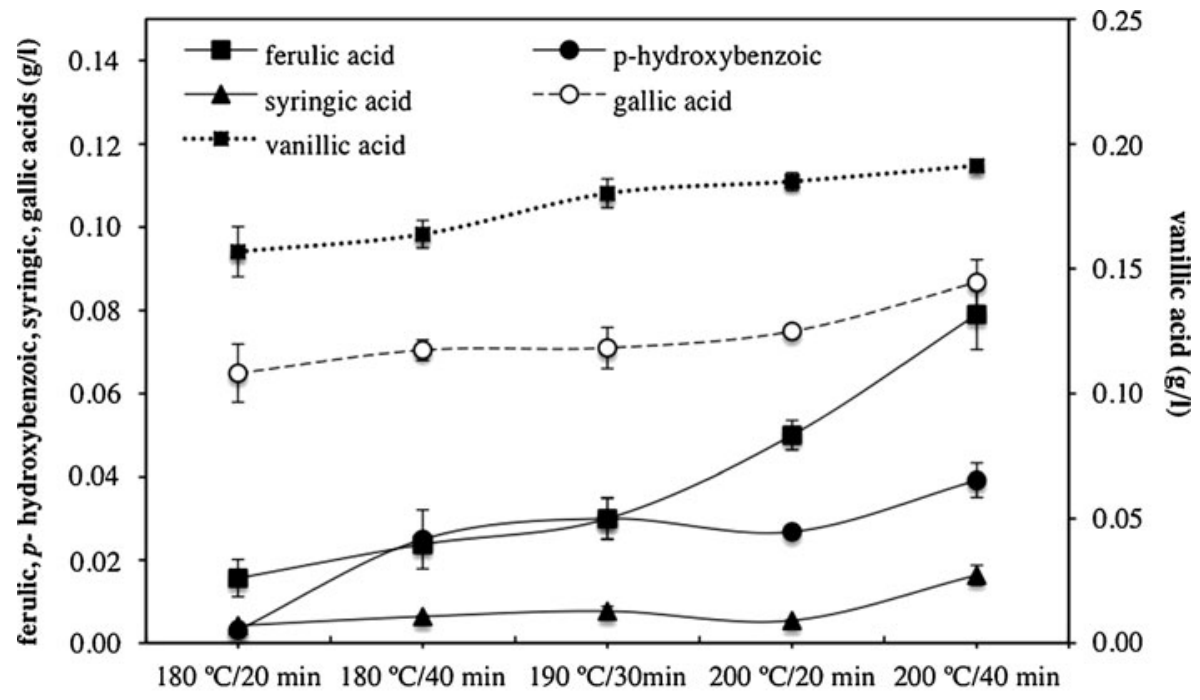

Operation Conditions

Fig. 1 Phenolic acids content (removal profiles) in the liquor obtained by organosolv process 
temperature and time are similar to those obtained using steam treatment and alkaline peroxide post-treatment, with higher recovery yields for vanillic acid and lower for ferulic acids [47].

\section{FTIR Spectra of Lignin Recovery}

Infrared spectroscopy is an effective way to identify the presence of certain functional groups in a molecule. Also, one can use the unique collection of absorption bands to confirm the identity of a pure compound or to detect the presence of specific impurities [48]. FTIR spectra of the obtained different lignin precipitates at different operation conditions were obtained between 3500 and $500 \mathrm{~cm}^{-1}$ (Fig. 2). FTIR spectra showed characteristic vibrations of typical LCM groups; carboxylic acids group is identified by the broad band centered in the region $3300-2700 \mathrm{~cm}^{-1}$, caused by the presence of the $\mathrm{O}-\mathrm{H}$ group that overlaps with the $\mathrm{C}-\mathrm{H}$ stretch band which appears near $3000 \mathrm{~cm}^{-1}$. Aldehyde type $\mathrm{C}-\mathrm{H}$ absorption bands are identified with two weak absorptions to the right of the $\mathrm{C}-\mathrm{H}$ stretch, near 2850 and $2600 \mathrm{~cm}^{-1}$. The three spectra of lignin extraction showed a similar broad band of the characteristic vibration of typical lignocellulosic materials at 2350 and $1740 \mathrm{~cm}^{-1}$, assigned to the aromatic ring $\mathrm{C}=\mathrm{C}$ and $\mathrm{C}-\mathrm{O}$ non conjugated bond, respectively. Some special absorption signals of lignin were observed in the $1460 \mathrm{~cm}^{-1}$ region,

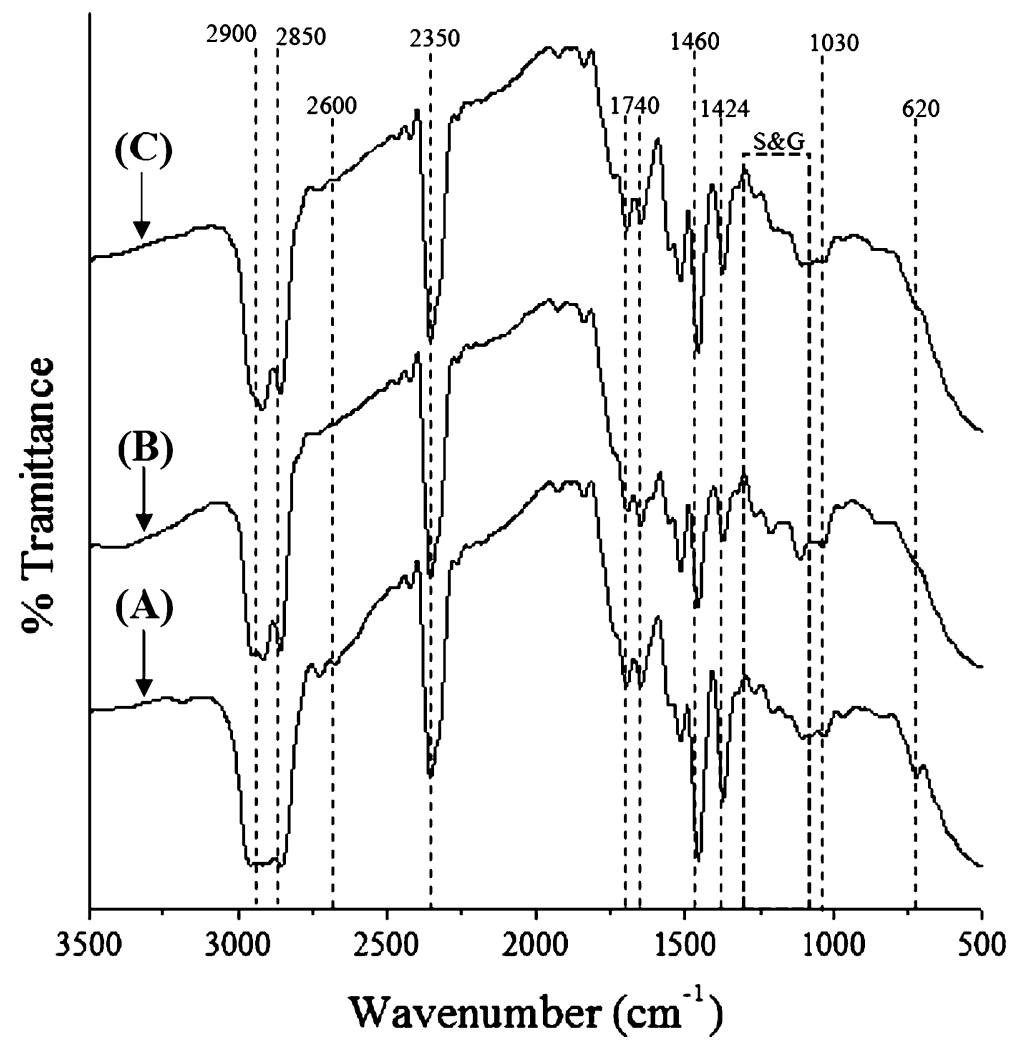

Fig. 2 FTIR spectra of lignin recovered by precipitation at different conditions: (A) $180^{\circ} \mathrm{C} / 20 \mathrm{~min} ;(\mathbf{B}) 190^{\circ}$ $\mathrm{C} / 30 \mathrm{~min}$; (C) $200^{\circ} \mathrm{C} / 40 \mathrm{~min}$ 
Fig. 3 X-ray diffraction curves of cellulose from wheat straw: a untreated wheat straw, b autohydrolysis at $180^{\circ} \mathrm{C} / 30 \mathrm{~min}$, c organosolv process at $180^{\circ} \mathrm{C} /$ $20 \mathrm{~min}$

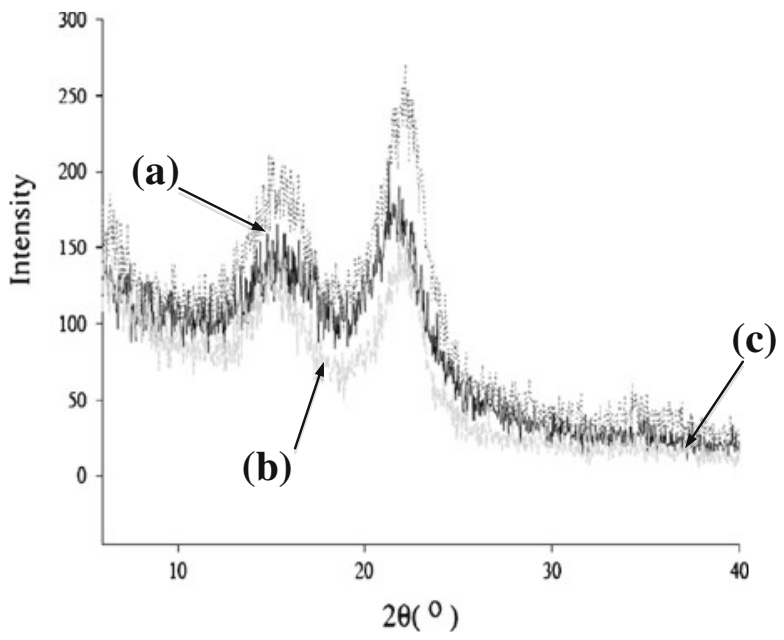

corresponding to $\mathrm{C}-\mathrm{H}$ deformations of methyl and methylene, showing the incidence of an intensive band that indicates highest methoxy content in the treatments at low time and temperature. Moreover, a decrease in the signals absorptions associated to syringyl (S) groups in the lignin $\left(1325 \mathrm{~cm}^{-1}\right)$ is observed, indicating a cleavage of the ether linkage and a certain degree of lignin demethoxylation during the most intense conditions of organosolv process. On the contrary, there was no deformation of the guayacyl $(\mathrm{G})$ units (1265$1130 \mathrm{~cm}^{-1}$ ) at the various conditions tested. Bands at $1120 \mathrm{~cm}^{-1}$ were assigned to $\mathrm{C}-\mathrm{O}$ and $\mathrm{C}-\mathrm{C}$ stretching vibrations.

\section{X-ray Diffraction}

Cellulose from wheat straw has crystalline and amorphous regions; these regions are affected by the different treatments applied to wheat straw. Figure 3 shows X-ray curves of cellulose samples from different treatments. The diffraction peaks around $15-16^{\circ}$ and $21-$ $22^{\circ}(2 \theta)$ are characteristics in the cellulose from wheat straw and their occurrence is in agreement with other works [49, 50]. The crystallinity index of $21.3 \%$ obtained for
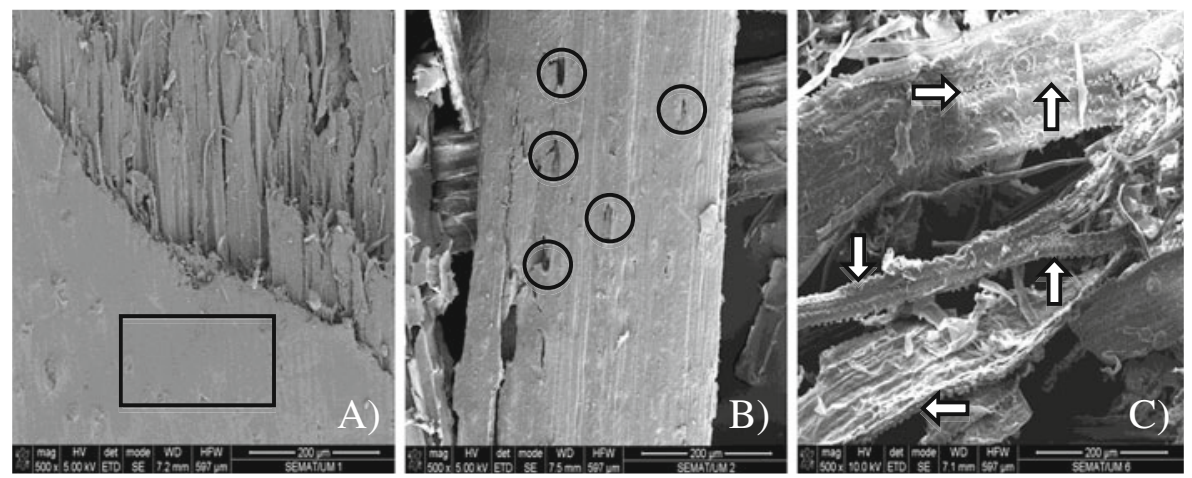

Fig. 4 Scanning electron microscopy images of treated and untreated wheat straw: (A) wheat straw, (B) autohydrolysis, (C) organosolv process: ordered fibers (black square), high porosity area (black circle), fiber matrix separation, and exposition (upright arrow) 
untreated wheat straw and its increase to $55.17 \%$ after autohydrolysis indicates significant structural changes. Removal of amorphous materials (lignin, hemicellulose) from lignocellulosic fractions and rearrangement of the remaining components have been associated with improved crystallinity [51]. According to the other works, increases of the crystallinity index values were observed following steam explosion and microwave digestion of sorghum bagasse $[52,53]$. For the crystallinity index obtained after the organosolv process was $53.59 \%$, indicating damages on the fiber structure and a more exposed cellulosic surface. Similar results have been reported in a previous work [54].

\section{Scanning Electron Microscopy}

SEM images presented in Fig. 4 were used to complete the analysis on the effect of the autohydrolysis and organosolv process on the structure. The untreated sample exhibited a rigid and highly ordered fibers (Fig. 4A). In contrast, the fibers obtained after autohydrolysis appeared to be distorted (Fig. 4B) because illustrated partition from the initial connected structure, increasing the external surface area and the porosity. In Fig. 4C, the fibers after the organosolv process are shown. Sample treated with organosolv process demonstrated a highly effect in fiber matrix separation and materials exposition, allowing to be more susceptible to enzymatic attack for subsequential use in fermentation processes.

\section{Conclusions}

This work shows that a sequential autohydrolysis and organosolv process is a suitable technology for hemicellulose sugars recovery mainly as the form of XOS and the generation of cellulose-enriched solids as well as the precipitation of lignin like a higher value product. Samples treated at $180^{\circ} \mathrm{C}$ and $30 \mathrm{~min}$ under autohydrolysis process showed a $44 \%$ of xylan conversion into xylooligosaccharides and under $180^{\circ} \mathrm{C}$ and $20 \mathrm{~min}$ the highest lignin recovery by organosolv precipitation $(3.25 \mathrm{~g} / 100 \mathrm{ml})$. Temperature and time as well as chemical structure were variables that showed a strong influence on lignin precipitation in the organosolv liquors. This research evidenced that the combination of autohydrolysis and organosolv process are an interesting alternative for add value of wheat straw compounds being in accordance with the "biorefinery" concept.

Acknowledgments The authors thank Professor Juan Carlos Parajó from University of Vigo, for the assistance in the materials preparation under autohydrolysis process as well as the ALBAN program for the $\mathrm{PhD}$ fellowship support.

\section{References}

1. Hongzhang, C., \& Liying, L. (2007). Bioresource Technology, 98, 666-676.

2. Turley, D. (2008), Introduction to chemicals from biomass, vol. 1: The chemical value of biomass. In: Clark, J., \& Deswarte F. (Ed.) (pp. 21-46). UK: John Wiley \& Sons.

3. Pan, X., Gilkes, N., Kadla, J., Pye, K., Saka, S., Gregg, D., et al. (2006). Biotechnology \& Bioengineering, 94, 851-861.

4. Montane, D., Farriol, X., Salvado, J., Jollez, P., \& Chornet, E. (1998). Biomass and Bioenergy, 14, 261276. 
5. Peterson, P. B. (1988). Agricultural Progress, 63, 8-23.

6. The agricultural production (2007). Available from: www.faostat.fao.org. Accessed April 5, 2010.

7. Garrote, G., Cruz, J., Moure, A., Dominguez, H., \& Parajo, J. (2004). Trends in Food Science and Technology, 15, 191-200.

8. Brunow, G. (2006), Biorefineries - Industrial processes and products, vol. 2: Lignin chemistry and its role in biomass conversion. In: Hopf, H., \& Anastas, P. (Ed.). (pp. 151-160). Weinheim, Ge: Wiley$\mathrm{VCH}$.

9. Fengel, D., \& Wegener, G. (1989). Wood: Chemistry, ultrastructure, reactions. NY: Walter de Gruyter.

10. Sjödahl, R. (2006), PhD thesis, Royal Institute of Technology, Stockholm, SE.

11. Mansouri, N., \& Salvado, J. (2006). Industrial Crops and Products, 24, 8-16.

12. Garrote, G., Eugenio, M. E., Díaz, M. J., Ariza, J., \& López, F. (2003). Bioresource Technology, 88, 6168.

13. Kleinert, T. N. (1974). Tappi Journal, 57, 99-102.

14. Aziz, S., \& Sarkanen, K. (1989). Tappi Journal, 72, 169-175.

15. Gonçalves, A., \& Ruzene, D. S. (2001). Applied Biochemistry and Biotechnology, 91-93, 63-70.

16. Gonçalves, A. R., \& Ruzene, D. S. (2003). Applied Biochemistry and Biotechnology, 105, 195-204.

17. Pan, X., Arato, C., Gilkes, N., Gregg, D., Mabee, W., Pye, K., et al. (2005). Biotechnology \& Bioengineering, 90, 473-481.

18. Muurinen, E. (2000). PhD thesis, University of Oulu, Oulu, Fi.

19. Arato, C., Pye, E. K., \& Gjennestad, G. (2005). Applied Biochemistry and Biotechnology, 121-124, 871882 .

20. Young, R. A., \& Akhtar, M. (1998). Environmentally friendly technologies for the pulp and paper industry (3rd ed.). NY: Wiley.

21. Ziaie, S., \& Mohammadi, J. (2007). Iranian Polymer, 16, 83-96.

22. Gilarrahz, M. A., Oliet, M., Rodriguez, F., \& Tijero, J. (1998). Canadian Journal of Chemical Engineering, 76, 253-260.

23. Jiménez, L., García, J. C., Pérez, I., Ariza, J., \& López, F. (2001). Industrial and Engineering Chemistry Research, 40, 6201-6206.

24. Gargulak, J., \& Lebo, S. (2000) In lignin: historical, biological, and materials perspectives, vol. 742: Commercial use of lignin-based materials. In: Glasser, W. G., Northey, R. A., \& Schultz, T. P. (Ed.). (pp. 304-320). Washington, DC: American Chemical Society.

25. Lora, J. (1992). Proceedings, Proc. VI Cong. Lat. Cel. Pap., Torremolinos, Spain.

26. Zhao, X., Cheng, K., \& Liu, D. (2009). Applied Microbiology and Biotechnology, 82, 815-827.

27. Jørgensen, H., Kristensen, J., \& Felby, C. (2007). Biofuels Bioprod Bioref, 1, 119-134.

28. Chum, H., Johnson, D., \& Black, S. (1990). Industrial and Engineering Chemistry Research, 29, 156162.

29. Browning, B. L. (1967). Methods of wood chemistry (1st ed.). NY: Interscience.

30. Ruiz, H., Ruzene, D., Silva, D., Quintas, M., Vicente, A., \& Teixeira, J. (2011). Journal of Chemical Technology and Biotechnology, 86, 88-94.

31. Garrote, G., Dominguez, H., \& Parajo, J. (2002). Journal of Food Engineering, 52, 211-218.

32. Carvalheiro, F., Fernandes, T., Duarte, L., \& Gírio, F. (2009). Applied Biochemistry and Biotechnology, 153, 84-93.

33. Carvalheiro, F., Garrote, G., Parajó, J., Pereira, H., \& Gírio, F. (2005). Biotechnology Progress, 21, 233243.

34. Garrote, G., Domínguez, H., \& Parajó, J. (2001). Holz als Roh- und Werkstoff, 59, 53-59.

35. Uloth, V., \& Wearing, J. (1989). Pulp and Paper of Canada, 90, 310-314.

36. Yoshida, M., Liu, Y., Uchida, S., Kawarada, K., Ukagami, Y., Ichinose, H., et al. (2008). Bioscience, Biotechnology and Biochemistry, 72, 805-810.

37. Fengel, D., \& Wegener, G. (1984). Wood chemistry, ultrastructure, reactions. Berlin: Walter de Gruyter.

38. Ruzene, D., Silva, D., Vicente, A., Gonçalves, A., \& Teixeira, J. (2008). Applied Biochemistry and Biotechnology, 147, 453-464.

39. Bjerre, A. B., Olesen, A. B., Fernqvist, T., Plöger, A., \& Schmidt, A. S. (1996). Biotechnology and Bioengineering, 49, 568-577.

40. Garrote, G., Falqué, E., Domínguez, H., \& Parajó, J. C. (2007). Bioresource Technology, 98, $1951-1957$.

41. Nabarlatz, D., Ebringerová, A., \& Montané, D. (2007). Carbohydrate Polymers, 69, 20-28.

42. Gullón, B., Alonso, J., \& Parajó, J. (2010). Bioresource Technology, 101, 6676-6684.

43. Vegas, R., Alonso, J., Domínguez, H., \& Parajó, J. (2004). Journal of Agricultural and Food Chemistry, 52, 7311-7317.

44. García, A., Toledano, A., Serrano, L., Egüés, I., González, M., Marín, F., et al. (2009). Separation and Purification Technology, 68, 193-198. 
45. Lawther, J., Sun, R., \& Banks, W. J. (1996). Agricultural and Food Chemistry, 44, 1241-1247.

46. Nimz, H. (1974). Angewandte Chemie International, 13, 313-321.

47. Sun, X. (2004). Polymer Degradation and Stability, 86, 245-256.

48. Faix, O. (1991). Holzforschung., 45, 21-27.

49. Gümüfikaya, E., \& Usta, M. (2002). Turkish Journal of Agriculture, 26, 247-252.

50. Liu, R., Yu, H., \& Huang, Y. (2005). Cellulose., 12, 25-34.

51. Öztürk, H., Potthast, A., Rosenau, T., Abu-Rous, M., MacNaughtan, B., Schuster, K., et al. (2009). Cellulose, 16, 37-52.

52. Carrasco, J., Sáiz, M., Navarro, A., Soriano, P., Saez, F., \& Martinez, J. (1994). Applied Biochemistry and Biotechnology, 45, 23-34.

53. Dogaris, I., Karapati, S., Mamma, D., Kalogeris, E., \& Kekos, D. (2009). Bioresource Technolnology, 100, 6543-6549.

54. Ouajai, S., \& Shanks, R. (2005). Polymers Degradation and Stability, 89, 327-335. 